\title{
A RECONSTRUÇÃO HISTÓRICA DO COLÉGIO COLÔNIA HOLANDESA: UMA INSTITUIÇÃO EDUCACIONAL DA IMIGRAÇÃO HOLANDESA EM ARAPOTI-PR
}

\author{
Carla Roseane de Sales Camargo ${ }^{1}$ \\ Rita de Cássia da Silva Oliveira ${ }^{2}$
}

\begin{abstract}
Resumo
A presente pesquisa refere-se ao trabalho de conclusão do Curso de Mestrado em Educação da Universidade Estadual de Ponta Grossa, a qual teve por objetivo investigar o processo histórico de reconstrução do Colégio Colônia Holandesa $(\mathrm{CCH})$ em Arapoti-PR. Para tanto, foi utilizada a metodologia da História oral (coleta de depoimentos orais) combinada com a análise das fontes documentais (o projeto político pedagógico e o regimento da escola). Por meio da memória dos depoentes, buscamos analisar o contexto de constituição do Colégio Colônia Holandesa a partir da chegada dos imigrantes holandeses em Arapoti no início da década de 1960, bem como identificar a organização e a concepção de educação da escola, buscando relacioná-la a política liberal e neoliberal. Sendo assim, a pesquisa desenvolvida buscou contribuir para a ampliação do conhecimento na área da História da Educação Brasileira, por meio de um recorte local, a educação dos imigrantes holandeses em Arapoti-PR.
\end{abstract}

Palavras-chave: História da educação. Imigração Holandesa. Colégio colônia Holandesa.

\section{THE HISTORICAL RECONSTRUCTION OF THE DUTCH COLONY COLLEGE: AN EDUCATIONAL INSTITUTION OF DUTCH IMMIGRATION IN ARAPOTI-PR}

\begin{abstract}
Abstact:
The present research refers to the work of conclusion of the Master Course in Education of the State University of Ponta Grossa, which aimed to investigate the process historical reconstruction of the Dutch Colony College $(\mathrm{CCH})$ in Arapoti-PR. For that, it was methodology of oral history (oral testimony collection) combined with the analysis of the documentary sources (the political pedagogical project and the school regiment). Through the memory of the context of the formation of the Dutch Colony College from the arrival of the Dutch immigrants in Arapoti in the early 1960s, as well as identifying the organization and conception of education of the school, seeking to relate it to liberal and neoliberal politics. Therefore, the research developed sought to contribute to the expansion of knowledge in the area of History of Brazilian Education, through a local clipping, the education of Dutch immigrants in Arapoti-PR.
\end{abstract}

Keywords: History of education. Dutch immigration. Dutch colony college. 


\title{
Revista HIISTEYIDIR On-line
}

A presente pesquisa refere-se ao trabalho de conclusão do Curso de Mestrado em Educação da Universidade Estadual de Ponta Grossa, a qual teve por objetivo investigar o processo histórico de reconstrução do Colégio Colônia Holandesa $(\mathrm{CCH})$ em Arapoti-PR a partir da chegada dos imigrantes holandeses em Arapoti no início da década de 1960, bem como identificar a organização e a concepção de educação da escola, buscando identificar os fatores que contribuíram para a saída desses imigrantes de sua pátria e a vinda para o Brasil.

Para a composição dessa pesquisa, não poderíamos nos conformar apenas com a análise de fontes documentais, pois apesar dos esforços empregados, pouquíssimos registros escritos foram encontrados, uma vez que, muitos foram destruídos e outros não foram preservados pelas novas gerações descendentes desses imigrantes.

Sendo assim, optamos pela História Oral combinadas com as informações coletadas em fontes documentais (o projeto político pedagógico e o regimento da escola) como metodologia, pois como diz Goldenberg "A combinação de metodologias diversas no estudo do mesmo fenômeno [...] tem por objetivo abranger a máxima amplitude na descrição, explicação e compreensão do objeto de estudo". (GOLDENBERG, 2002, p. 63). O cotejo e o cruzamento de indícios coletados através de técnicas variadas tendem a contribuir para a riqueza das informações e, consequentemente, para o produto final do estudo.

Dessa forma, foram entrevistados três ex-alunos da escola, os quais serão chamados de sujeito (S) e foram numerados de 1 a 3 ao longo dessa pesquisa. As entrevistas constituíram a fonte principal desse trabalho. Para Verena Alberti (2004, p. 27),

\begin{abstract}
A metodologia de história oral é bastante adequada para o estudo de memórias, isto é, de representações do passado. Estudar essa história é estudar o trabalho de constituição e formalização das memórias, continuamente negociadas. A constituição da memória é importante porque está atrelada à construção da identidade. Como assinala Michael Pollak, a memória resiste à alteridade e à mudança e é essencial na percepção de si e dos outros. Ela é resultado de um trabalho de organização e de seleção daquilo que é importante para o sentimento de unidade, de continuidade e de coerência - isso é, de identidade. E porque a memória é mutante, é possível falar de uma história das memórias de pessoas ou grupos, passível de ser estudada através de entrevistas de história oral.
\end{abstract}

$\mathrm{Na}$ análise das entrevistas realizadas com os ex-alunos da escola, buscamos a partir das suas histórias de vida, identificar a organização e a concepção de educação do CCH.

Cabe ressaltar ainda, que como foi utilizada a metodologia da História oral nesta, recorremos aos recursos gráficos "Itálico" e as "aspas" para a identificação das falas dos entrevistados, uma vez que, as entrevistas constituíram a fonte principal desse trabalho.

Essa pesquisa está organizada em três partes. Na primeira, buscamos elencar alguns fatores que contribuíram para a saída dos imigrantes holandeses de sua pátria e a vinda para o Brasil. Na segunda parte, analisamos o contexto de constituição do Colégio Colônia Holandesa a partir da chegada dos imigrantes holandeses em Arapoti na década de 1960. Finalmente, na última parte, por meio de depoimentos de ex-alunos da escola, investigamos a concepção de educação da escola, buscando relacioná-la a política liberal e neoliberal. 


\section{A HOLANDA DO SÉCULO XIX: SAÍDA DOS IMIGRANTES EM BUSCA DE NOVAS POSSIBILIDADES}

Ao longo do século XIX, o Estado holandês se consolidaria sob um regime monárquico e princípios constitucionais, principalmente com a Constituição de 1848. Durante o reinado da Rainha Guilhermina (de 1890 até o ano de 1948), o cenário político europeu foi marcado pelas duas grandes guerras mundiais. Já no início do século XX, os tempos de crise enfrentados pela população europeia evidenciavam-se, também, no intenso movimento migratório. Grandes populações eram atingidas pela mobilidade, tanto no sentido campo-cidade, como na opção pela travessia oceânica, em busca de novos horizontes e perspectivas melhores de vida. Para os holandeses, não seria diferente. (CHAVES, 2011, p. 17).

Para entender porque milhões de europeus deixaram suas pátrias, três fatores são apontados como predominantes: “[...] o primeiro é o acesso à terra e, portanto, ao alimento; o segundo, a variação da produtividade da terra; e o terceiro, o número de membros da família que precisam ser mantidos”. (CHAVES, 2011. p. 18 apud KLEIN, 1999, p. 14).

Sendo assim, alguns desses fatores podem ser observados no relato de Hilbert Kok ${ }^{3}$, o qual explicita que após a Segunda Guerra Mundial, vários países passaram por muitas dificuldades, falta de recursos, inclusive a Holanda. As famílias eram grandes e faltava espaço, terras para serem divididas entre os filhos. Então, as famílias resolveram vir para o Brasil em busca de melhores condições de vida para seus filhos.

Podemos dizer que além da busca por "novas possibilidades", os imigrantes também eram incentivados pelo governo brasileiro, o qual objetivava reocupar os chamados "espaços vazios" do território brasileiro (já ocupados por índios e caboclos); e também intermediados por uma Comissão de Imigração na Holanda, que mantinha contato com as colônias de Carambeí e Castro já instaladas no Paraná, novas levas de famílias holandesas vieram para a região. (CAMARGO; BENATTE, 2014, p. 222).

O governo brasileiro além de buscar reocupar os chamados espaços vazios do território brasileiro, objetivava também promover o branqueamento do país, facilitando e dando preferência a vinda de imigrantes europeus para o mesmo.

Acerca do objetivo de branquear o país, Furtado (2000), citado por Nascimento (2008, p. 42) afirma que "[...] havia nítido racismo da parte daqueles que faziam a política imigratória. Daí porque se deu preferência grandemente à imigração dos europeus: alemães, italianos, poloneses".

A elite cultural do país apostava na vinda dos imigrantes europeus, baseados na "[...] suposta "superioridade inata" de alguns povos europeus para o trabalho. (KREUTZ, 2005, p. 152).

Dessa forma, Nascimento (2008, p. 42) explicita que “[...] durante o século XIX, o objetivo de branqueamento do país determinava a escolha das etnias que deveriam imigrar para o Brasil". A imigração havia sido favorecida pelas políticas oficiais com o objetivo de desenvolver o país, tendo-se como referência os Estados Unidos, uma vez que, este passava 


\section{Revista HIISTEYIDIR On-line}

Artigo

doi: 10.20396/rho.v17i4.8651242

por um rápido desenvolvimento. Por isto, a formação de núcleos rurais etnicamente homogêneos foi favorecida, inicialmente, pelas políticas oficiais. (KREUTZ, 2005, p. 154).

Os imigrantes vinham para o Brasil com a promessa de ocupar um território próprio, onde poderiam se desenvolver com autonomia nas suas colônias, com liberdade de ministrar ensino para os seus filhos na sua língua pátria, sendo isentos de impostos e outros malefícios, desde que habitassem no local e produzissem para abastecer o mercado interno. (KREUTZ, 2005, p. 41).

Conforme a historiadora Hilda de Oliveira Ladeira (1976, p. 17), principalmente depois da emancipação política (1853), o Paraná começou a atrair imigrantes que, inicialmente, colonizaram as vizinhanças da capital, tanto na região dos campos de Curitiba como nas regiões limítrofes de florestas. Incrementou-se um tipo de colonização basicamente orientada para o estímulo de uma agricultura que suprisse as necessidades de abastecimento. Providências conjuntas dos governos imperial e provincial permitiram o estabelecimento de núcleos coloniais nas proximidades dos centros urbanos, sobretudo no planalto de Curitiba. (CAMARGO; BENATTE, 2014, p. 221).

No Paraná, duas décadas depois da instalação da Província, a colonização com base no imigrante entrou em sua fase mais intensa: de 1868 a 1878 instalaram-se alguns núcleos coloniais por iniciativa oficial ou particular. A intensificação da propaganda imigratória no exterior, a construção de ferrovias, a abolição da escravatura e a proclamação da república intensificaram a entrada de imigrantes, alcançando quotas anuais de 200 mil imigrantes por ano. (CAMARGO; BENATTE, 2014, p. 221).

A imigração introduziria no meio rural paranaense uma relativa mudança na estrutura agrária, com possibilidades de acesso à pequena e à média propriedade. Em busca dessas novas "possibilidades", muitos imigrantes holandeses desembarcaram no Paraná, em fins do século XIX e início do XX. Os primeiros a chegarem foram os irmãos Jan e Leendert Verschoor e Jan Vriesman. Primeiramente, fixaram-se na cidade de Irati, fundando a colônia de Gonçalves Junior. (CORDEIRO, 2007, p. 41 apud CAMARGO; BENATTE, 2014, p. 221).

No entanto, a distância dessa cidade dos centros consumidores (aproximadamente 100 quilômetros de Ponta Grossa), a incidência de doenças como a malária, a falta de água potável e de assistência médica, entre outras dificuldades, forçou o retorno de grande parte desses imigrantes à Holanda. (CORDEIRO, 2014, p. 221).

Os que decidiram ficar migraram para Carambeí, fundando em 1911, uma colônia agrícola. Segundo Ladeira (1976, p. 21), a maioria desses homens e mulheres, originários das docas de Roterdã, jamais haviam trabalhado a terra; encontravam-se desempregados e vieram "refazer a vida" no Brasil. Apesar das dificuldades iniciais enfrentadas na Colônia Gonçalves Junior, o pequeno grupo de imigrantes (em torno de 52 pessoas) estabeleceu-se em Carambeí dedicando-se inicialmente à cultura de trigo; logo intensificaram a criação de gado leiteiro visando obter adubo orgânico necessário à fertilização dos campos. O relativo sucesso da colonização holandesa em Carambeí, constatado pela visita oficial do Embaixador Holandês em 1933, estimulou a vinda de novos contingentes imigratórios. (LADEIRA, 1976, p. 222). 
Em 1951, uma nova colônia - Castrolanda - foi fundada na região dos Campos Gerais- PR. O município de Castro foi apontado como ideal para o estabelecimento de uma nova colônia pela sua proximidade com a colônia de Carambeí. Castrolanda situa-se a $6 \mathrm{~km}$ a sudoeste de Castro, cidade-sede do município. A fundação dessa colônia tinha como principal objetivo econômico a produção de laticínios para somar-se à produção da colônia de Carambeí. (CORDEIRO, 2014, p. 222).

Segundo Ladeira (1976, p. 31), para atender a necessidade de aumentar a produção do leite e o crescimento natural da população, os holandeses estabelecidos em Carambeí e Castrolanda decidiram elaborar um projeto de imigração e colonização. Este previa a compra de seis mil hectares de terra para a instalação de 100 famílias, compostas por $60 \%$ de novos imigrantes e $40 \%$ de famílias das colônias já existentes. Tal projeto culminou na fundação de um novo núcleo na região - a colônia Holandesa de Arapoti. (CORDEIRO, 2014, p. 222).

Arapoti localiza- se no interior do Paraná, numa colina cercada de campos e pastagens naturais, na zona fisiográfica dos Campos Gerais. Em 1934, foi elevada à categoria de município.

Inicialmente, a Lei Municipal n. ${ }^{\circ}$ 02, de 8 de outubro de 1908, criou o Distrito Judiciário de Cerrado, primeiro nome dado ao lugar.

Em 1912, iniciou-se a construção da estrada de ferro que cortaria o município. Assim, a partir dessa data, a cidade recebeu imigrantes de origem espanhola e polonesa, os quais vieram para trabalhar na construção dessa estrada de ferro. No ano de 1913, foi inaugurada a estação ferroviária denominada Cachoeirinha.

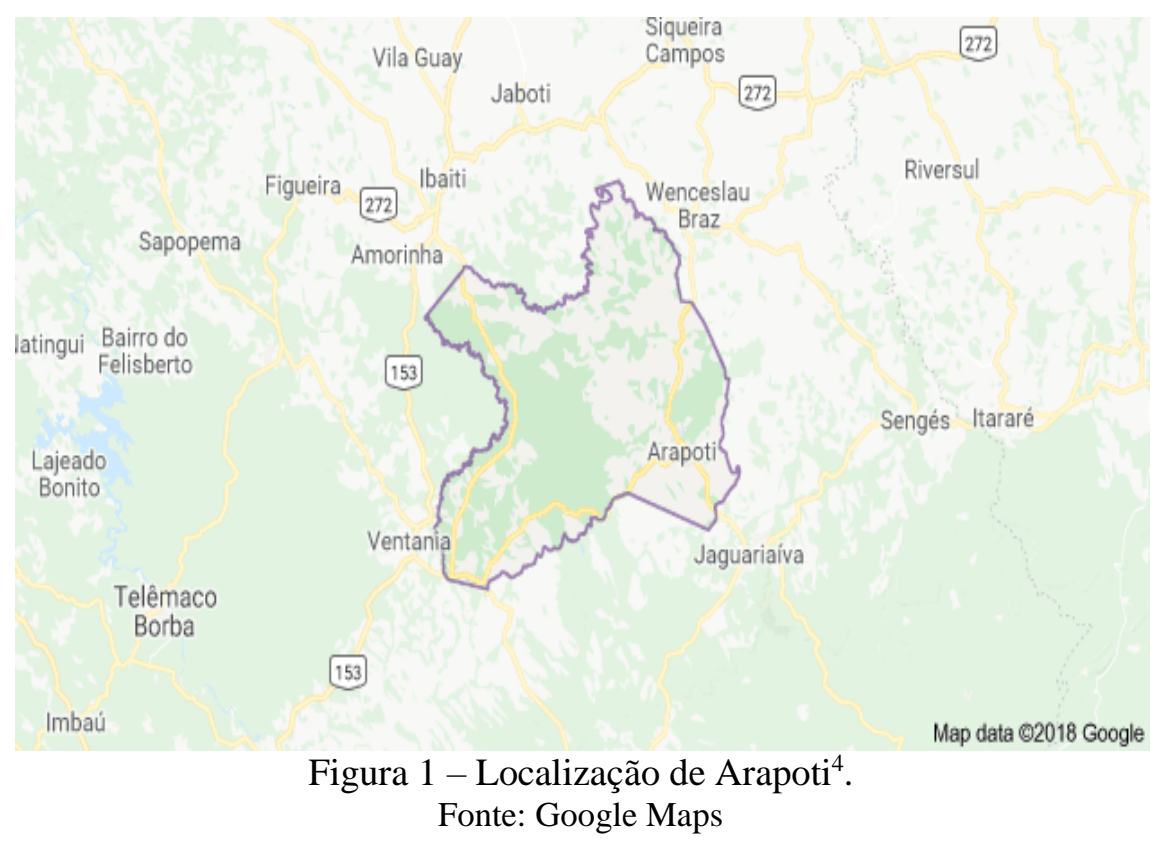

Em 1934, Cachoeirinha passa a ser Distrito Administrativo de Jaguariaíva. O Decreto-Lei Estadual n. ${ }^{\circ}$ 199, de 30 de dezembro de 1943, alterou a denominação de Cachoeirinha para Arapoti, sendo assim, emancipou-se como município e cidade em 18 de dezembro de $1955^{5}$. 


\section{Revista HIIST'TEIDBR On-line}

Os imigrantes holandeses chegaram em Arapoti em junho de 1960. Segundo relato de Hilbert Kok, a viagem de navio durou dezessete dias, foi tranquila, no entanto, a vinda do porto de Santos a Arapoti foi difícil, uma vez que não havia estradas asfaltadas e pavimentadas. A chegada dos mesmos também causou momentos de tensão; sabiam que seriam recebidos por migrantes da colônia Castrolanda, já instalados na sede da fazenda comprada pelas colônias de Carambeí e Castrolanda com o objetivo de aumentar a produção de laticínios; e que teriam, a partir de então, que conviver cotidianamente com pessoas que desconheciam, sejam imigrantes já estabelecidos, sejam nacionais. (CAMARGO; BENATTE, 2014, p. 223).

Ao chegarem, as seis primeiras famílias imigrantes se depararam com apenas três casas prontas, além da casa da fazenda que serviu de casa pastoral para o pastor Muller e um barracão, imediatamente transformado em escola e igreja. Logo começaram a construir outras casas provisórias, e em seis meses levantaram a primeira igreja, a primeira escola e o primeiro barracão da Cooperativa Agroindustrial (CAPAL) com vinte e um sócios, todos de nacionalidade holandesa. (CAMARGO; BENATTE, 2014, p. 223). Segundo os dados do IBGE de 2008, possui aproximadamente 30.000 habitantes.

\section{CONSTITUIÇÃO DO COLÉGIO COLÔNIA HOLANDESA EM ARAPOTI-PARANÁ}

A escola primária, frequentada pelos descendentes de imigrantes holandeses em Arapoti, foi fundada em julho de 1960, devido a necessidade de oferecer aos seus filhos em idade escolar, o ensino de Língua Portuguesa e a adaptação aos costumes da nova Pátria. (PROJETO POLÍTICO PEDAGÓGICO, 2009, p. 5).

O Colégio Colônia Holandesa, desde o seu início, teve como entidade mantenedora a Igreja Evangélica Reformada, a qual contribui com a administração financeira do Colégio, desenvolve um trabalho de fiscalização e distribuição da renda obtida por meio de suas mensalidades, sendo aplicada na sua totalidade em benefício da escola, não revertendo nenhum valor para seus membros mantenedores. (PROJETO POLÍTICO PEDAGÓGICO, 2009, p. 13).

Segundo Ian Hagen ${ }^{5}$, nos primeiros quatro meses a escola e a Igreja funcionavam no mesmo espaço. Durante a semana, o barracão de madeira, abrigava a escola, e aos finais de semana, a Igreja Evangélica.

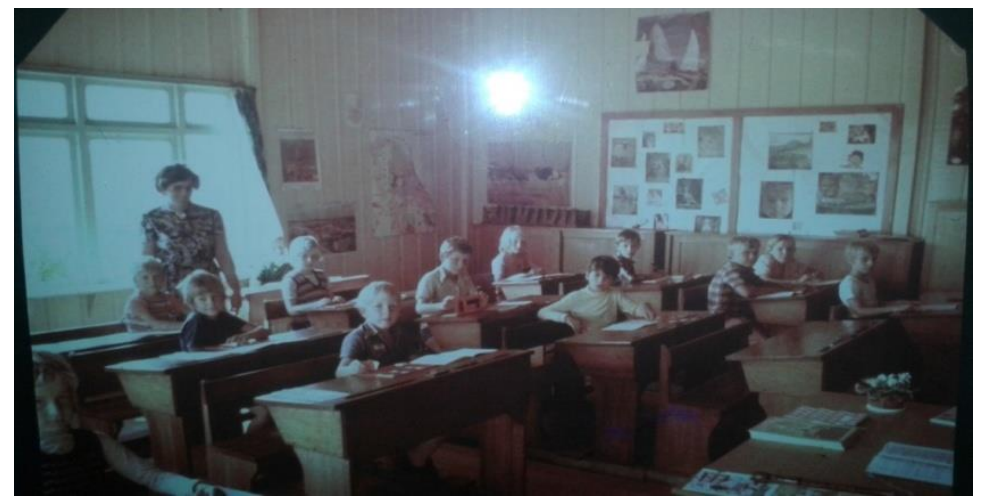


Fotografia 01 - Escola- Sala de aula. Fonte: Museu o Imigrante Holandês- Arapoti-PR

Inicialmente, a escola atendia num único espaço, aproximadamente, vinte e cinco crianças de diferentes idades e níveis de aprendizagem. Nesses quatro meses, o ensino ficou por conta de Anny Koopman, a qual trabalhava como auxiliar de limpeza na Escola Holandesa de Castrolanda. Embora não fosse formada para ser professora, Anny Koopman recebeu orientações do professor Epema, também da Escola de Castrolanda, de como deveriam ocorrer as aulas numa escola com crianças de diferentes idades e níveis de aprendizagem.

Posteriormente, chegou na colônia de Arapoti, a professora Relindes Bornmann, a qual veio de Castro. Descendente de imigrantes alemães, a referida professora ensinava o ensino da Língua Portuguesa.

Assim, podemos dizer que embora no início, a maior preocupação dos imigrantes fosse aprender a Língua Portuguesa, eles nunca abandonaram a sua língua materna, a sua cultura. Isso pode ser evidenciado por meio do depoimento: "Tínhamos aulas todos os dias, de Português e Holandês. De manhãa, Português e a tarde de Holandês, precisamos preservar a nossa cultura". (S1).

Conforme um dos depoentes "[...] a professora falava em holandês e pedia para que os alunos traduzissem em português. Ela nos ensinava a Língua Portuguesa por meio de hinos evangélicos". (S1).

Os imigrantes holandeses se preocuparam desde o início com uma educação “[...] tanto no sentido amplo, da formação de valores morais e religiosos, quanto no sentido estrito, da escolarização". (CHAVES, 2011, p. 39).

No início da década de 1960, o Brasil foi marcado por uma intensa efervescência cultural e política. Os princípios do nacional-desenvolvimentismo marcado pelos investimentos em áreas como a educação, a industrialização, a energia, o setor de transportes e a alimentação gerados por Getúlio Vargas e Juscelino Kubitschek na década de 1950, geraram bons resultados e atingiram camadas cada vez maiores da sociedade brasileira. (KAPP et al., 2011, p. 58).

Cabe ressaltar ainda que a década de 1960, foi marcada pelo golpe civil-militar de 1964 no país, o qual deu início a ditadura militar no mesmo.

[...] foram vinte longos anos que impuseram à massa dos brasileiros a despolitização, o medo e a mordaça: a ditadura oprimiu (através dos meios mais variados, da censura à onipresença policial-militar), reprimiu (chegando a recorrer a um criminoso terrorismo do Estado) e deprimiu (interrompendo projetos de vida de gerações, destruindo sonhos e aspirações de milhões e milhões de homens e mulheres). Para durar por duas décadas, o regime do $1^{\circ}$ de abril de 1964 teve que perseguir, exilar, torturar, prender e assassinar (e/ ou fazendo "desaparecer") operários e trabalhadores rurais, sindicalistas, estudantes, artistas, escritores, cientistas, padres e até mesmo burgueses e militares que tinham compromissos com a democracia- o que significa que aqueles vinte anos foram também de resistência. (NETTO, 2014, p. 17). 
Podemos dizer que esse período marcou profundamente a história do país, pois foram implementadas mudanças nos âmbitos- social, econômico e educacional. Neste último, teve início uma nova corrida contra o tempo pelo atraso da educação, "[...] com a implementação de políticas de reformulação do ensino técnico, industrial e secundário e programas de qualificação para trabalhadores, visando suprir as carências de trabalhadores qualificados para a indústria nacional”. (NETO, 2015, p. 189). e 1970 ,

Sendo assim, na educação, ocorreu um processo de expansão do ensino. Entre 1940

[...] houve um intenso crescimento demográfico e urbanização. Estes dois fatores acabaram por provocar um aumento de demanda potencial e da procura efetiva de educação escolar. Essa procura abrangeu tanto a população de idade própria para a escolarização, quanto a população que, fora da faixa etária, se encontrava marginalizada pelo sistema educacional, sem ter recebido, nem em tempo certo, nem em quantidade mínima, a educação sistemática de que necessitava. (ROMANELLI, 1978, p. 74).

Ainda para Romanelli (1978), a expansão do ensino no Brasil nesse período (19401970) pode ser observado no aumento efetivo da matrícula escolar realizada em todos os níveis de ensino: ensino primário, ensino médio e ensino superior.

No entanto, apesar de se ter evidenciado nesse período um progresso no setor do ensino, a autora afirma que essa expansão não esteve isenta de deficiências quantitativas da expansão do ensino.

A partir da análise de dados quantitativos ${ }^{6}$, Romanelli (1978) explicita que as deficiências quantitativas da expansão do ensino entre 1940-1970, podem ser explicadas a partir da análise de três aspectos da marginalização educacional: a oferta insuficiente, o rendimento interno do sistema escolar e a discriminação social.

Quanto a oferta insuficiente, a autora afirma que a expansão do ensino não foi suficiente para atingir a população em idade própria (população de 5 a 24 anos) para receber educação escolar, pois em 1970, cerca de $70 \%$ dessa faixa etária ainda permaneceram fora das escolas.

Em relação ao rendimento interno do sistema escolar, Romanelli (1978, p. 93) declara que:

[...] o alto grau de seletividade do sistema, "peneirando" a maior parte da população que nele ingresse, no decorrer da vida escolar, faz com que exista enorme descompasso entre os diferentes níveis e, sob alguns aspectos, num mesmo nível, entre as várias espécies que o compõem [...] de cada 1.000 alunos admitidos à $1^{\text {a }}$ série primária, em 1960, apenas 56 tenham conseguido ingresso no ensino superior, em 1971, conforme dados do Ministério da Educação e Cultura.

Os fatores atuantes no processo de seletividade escolar podem ser explicitados a partir dos relacionados com o contexto global, em que se instala a escola, e os relacionados com a ordem interna do sistema. (ROMANELLI, 1978, p. 93).

No primeiro caso, encontram-se os fatores de ordem econômica, social e cultural, que atuam sobre o aluno, no intuito de fazê-lo enfrentar, na escola, uma luta desigual para assegurar sua permanência, como por exemplo, o estado de penúria da família, o qual impossibilita a aquisição de material escolar e alimentação adequada, até a necessidade de a 


\section{Revista HIISTEYIDIR On-line}

Artigo

doi: $10.20396 /$ rho.v17i4.8651242

família transformar todos os seus membros ativos, inclusive os mais jovens, em trabalhadores para garantir, através da maior quantidade de trabalho à venda e sua sobrevivência. (ROMANELLI, 1978, p. 93).

No segundo caso, pesa fortemente no rendimento escolar a estrutura arcaica da escola, que resiste a qualquer tentativa de modernização. Acerca desses fatores Romanelli (1978, p. 94) declara que:

[...] a existência de métodos tradicionais de ensino e avaliação; a ênfase na retenção de conhecimentos inúteis; a falta de recursos, materiais adequados, a alta procentagem de professores leigos e mal preparados são alguns dos fatores responsáveis pelo baixo índice de rendimento do sistema.

Em relação ao funcionamento da Escola Rural da Colônia Holandesa em 1961, um dos depoentes declara que "Tínhamos aulas todas as manhãs de Português, Matemática, Geografia, História, Ciências, Ensino Religioso e a tarde aulas de Holandês. A professora Relindes era bastante rígida, tinha jeito alemão. Ela falava em Holandês e nós traduzíamos para o Português [...] Se alguma criança respondesse errado nos testes orais, era castigada: ela batia com a régua na nossa mão ou nos fazia ajoelhar em grãos de milhos". (S1).

Evidenciamos a partir da narrativa acima, que em relação a prática pedagógica não havia método de prática de ensino específico, bem como volta-se ao ensino tradicional ao priorizar a organização da classe, sob disciplina rígida em função da recepção do conteúdo, o professor como transmissor do conhecimento e o aluno como mero receptor dos conhecimentos transmitidos pelo professor.

Quanto ao terceiro aspecto da marginalização educacional, a discriminação social, a autora declara que:

[...] na década de 1960, o Estado passou a reconhecer, como válido, o mesmo ensino dado em todas as escolas, quer tivessem elas ou não as mesmas condições de funcionamento [...]. Na verdade, o direito de todos à educação não passou, na vida real da sociedade, do direito de todos aqueles que se mostrassem capazes, segundo os padrões ditados pelos valores das classes dominantes. (ROMANELLI, 1978, p. 105).

No Brasil, esses aspectos de conteúdo e métodos aplicados ao ensino, segundo os valores alheios aos reais valores das classes populares, são muito responsáveis pelo revés, na escola, de significativa parcela da população e pelas condições de desigualdade com que lutam essas classes pelo acesso à escola. (ROMANELLI, 1978, p. 105).

Em 1961 foi fundada a Escola Rural da Colônia Holandesa, a qual passou a funcionar em um novo prédio de madeira construído pela própria comunidade da Colônia. Esta sob a responsabilidade da professora Relindes Bornmann, a qual exercia papel de professora e diretora ao mesmo tempo, continuava a atender uma clientela escolar de $1^{\mathrm{a}}$ a $3^{\mathrm{a}}$ série, em forma de classe multisseriada. E em 1962, implantou-se a última série do primário, isto é, a $4^{\mathrm{a}}$ série, continuando em regime multisseriado. (PROJETO POLÍTICO PEDAGÓGICO, 2009, p. 5).

Neste mesmo ano é sancionada a primeira Lei de Diretrizes e Bases da Educação Nacional (Lei $\mathrm{n}^{\circ} 4.024 / 61$ ), a qual sinalizou um grande avanço para a unificação do ensino no país. 
A Lei 4024/61 previa a obrigatoriedade do ensino primário, no entanto, a oferta insuficiente de escolas mantidas pelo poder público em Arapoti, incentivou os imigrantes holandeses a construírem uma escola própria na Colônia de Arapoti.

Já em relação ao Ensino Médio, o art. 36 da Lei 4024/61 assegurava que:

Art. 36. O ingresso na primeira série do $1^{\circ}$ ciclo dos cursos de ensino médio depende de aprovação em exame de admissão, em que fique demonstrada satisfatória educação primária, desde que o educando tenha onze anos completos ou venha a alcançar essa idade no correr do ano letivo. (BRASIL, 1961).

Conforme relato de um depoente, a maioria dos imigrantes holandeses que contavam com onze anos ou mais ao chegarem à Arapoti, não foram para a escola, pois com essa idade já haviam concluído o ensino primário na Holanda.

Dessa forma, a oferta insuficiente de escolas de segundo grau, bem como à distância da Colônia até a cidade de Arapoti, fizeram com que esses imigrantes não prosseguissem seus estudos e se dedicassem exclusivamente, a ajudar as famílias na agricultura e na leiteria.

Os alunos imigrantes ao concluírem o ensino primário na escola da colônia, eram transferidos para a Escola Estadual Rui Barbosa, localizada na cidade de Arapoti. Esta escola era a única do município a ofertar o ginásio e o colegial.

As dificuldades encontradas pelos imigrantes para prosseguirem seus estudos, bem como as primeiras impressões obtidas no trajeto entre a Colônia e a Cidade de Arapoti continuam vivos na memória do grupo, conforme o relato de um dos depoentes: "O Ginásio só tinha na cidade, e este funcionava a noite. Nós íamos a cavalo ou de bicicleta. O retorno para casa era muito difícil, pois quase não enxergavamos o caminho na escuridão. Em dias chuvosos, o retorno era ainda pior". (S1).

A Lei 4.024/61 foi uma oportunidade com que contou a sociedade brasileira para organizar seu sistema de ensino, pelo menos em seu aspecto formal, de acordo com o que reivindicava o momento, em termos de desenvolvimento. (ROMANELLI, 1978, p. 185).

A partir de 1961 a Escola Rural da Colônia Holandesa recebeu professores vindos de diversas partes da Holanda, bem como também passou a contratar, em 1962, professoras brasileiras.

Entre os anos de 1964 e 1985, o Brasil viveu sob o domínio de uma ditadura militar. Nesse período, o país foi comandado por presidentes originários do alto oficialato do Exército e indicados pela cúpula militar para ocupar o cargo, sem qualquer interferência ou participação da sociedade nesse processo. (KAPP et al., 2011, p. 76).

As rupturas ocorridas nesse período atingiram tanto o campo político-administrativo quanto o econômico.

[...] a ruptura política foi necessária para preservar a ordem socioeconômica, pois se temia que a persistência dos grupos que então controlavam o poder político formal viesse a provocar uma ruptura no plano socioeconômico. Destaque-se que esse fenômeno de ruptura política para a preservação da ordem socioeconômica foi constantemente proclamado pelos discursos políticos proferidos por ocasião das comemorações cívico-militares ao longo dos vinte anos da ditadura. (SAVIANI, 2008, p. 364). 


\title{
Revista HIISTEYIDIR On-line
}

As manifestações populares, os movimentos grevistas, as publicações que constestavam o regime e a livre produção cultural também foram duramente combatidas pelos presidentes militares, pois eram vistas como um risco para a ordem estabelecida. (KAPP et al., 2011, p. 77).

Além das mudanças apontadas acima nos campos político-administrativo e econômicos, a educação brasileira, também vivenciou mudanças, pois teve que procurar atender os interesses da estrutura de poder instaurada. Sobre as mudanças ocorridas a partir de 1964,

\begin{abstract}
[...] o sistema educacional foi marcado por dois momentos distintos. O primeiro, atrelado a implantação do regime e à política de recuperação econômica, constatou-se uma aceleração do ritmo do crescimento da demanda social de educação, o que provocou, consequentemente, um agravamento da crise do sistema educacional.

Já o segundo momento se consubstanciou no delineamento de uma política de educação que já não via apenas na urgência de se resolverem problemas imediatos, ditados pela crise. Mais do que isso, o regime percebeu por influência da assistência técnica dada pela USAID, a necessidade de se adotarem, em definitivo, as medidas para adequar o sistema educacional ao modelo do desenvolvimento econômico que então se intensificava no Brasil. (ROMANELLI, 1978, p. 196).
\end{abstract}

Assim, sob a influência de acordos internacionais como o MEC- USAID ${ }^{7}$, foi aprovada em 1971, a Lei 5.692, a qual apresentava uma reforma no antigo ensino primário e médio, instaurando o ensino de $1^{\circ}$ e $2^{\circ}$ graus.

Dentre as mudanças introduzidas na estrutura do ensino pela Lei 5.692, podemos citar a ampliação da obrigatoriedade escolar para 8 anos, compreendendo a faixa etária dos 7 aos 14 anos. Essa ampliação, também aumentou as obrigações do Estado com relação à educação do povo, uma vez que, a expansão do ensino decorrente desta Lei, passou a exigir uma maior capacidade de adaptação à realidades inexistentes nos tradicionais cursos primário e ginasial. (ROMANELLI, 1978, p. 237).

Os objetivos gerais da nova Lei 5.692/71 permanecem idênticos aos da Lei anterior (4.024/61), podendo ser observados em seu art. $1^{\mathrm{o}}$ :

Art. $1^{\circ} \mathrm{O}$ ensino de $1^{\circ}$ e $2^{\circ}$ graus tem por objetivo geral proporcionar ao educando a formação necessária ao desenvolvimento de suas potencialidades como elemento de auto-realização, gualiticação para o trabalho e preparo para o exercício consciente da cidadania. (BRASIL, 1971).

Ainda em relação a estrutura do ensino, Romanelli (1978, p. 237) explicita que a reforma educacional de 1971 ampliou a obrigatoriedade escolar para oito anos, eliminando assim, um dos pontos de estrangulamento do nosso antigo sistema representado pela passagem do primário ao ginasial, passagem que era feita mediante os chamados exames de admissão; bem como eliminou o dualismo antes existente entre escola secundária e escola técnica, criando uma escola única de $1^{\circ}$ e $2^{\circ}$ graus, sendo que o primeiro grau, visava além da educação geral fundamental, à sondagem vocacional e iniciação para o trabalho, e o segundo grau com vistas à habilitação profissional de grau médio.

Dessa forma, sob a égide da Lei 5.692, em 1977, o prédio de madeira da Escola Colônia Holandesa foi demolido, dando lugar a um novo prédio de alvenaria, construído 
pela Fundação Educacional do Paraná (Fundepar), instituída em 1962. E no ano seguinte, foi construído um prédio adequado ao atendimento de crianças de 4 a 6 anos, o qual funcionava em caráter experimental e oferecendo assistência aos filhos de funcionários da Fábrica de queijos e da Cooperativa Capal, empresas criadas e mantidas pelos imigrantes holandeses.

Em 1979, a Escola Colônia Holandesa passou por algumas mudanças: deixou de funcionar na modalidade multisseriada, passou a atender alunos da zona rural e urbana do município de Arapoti, bem como ampliou o quadro de professores. Neste ano, foram contratadas duas professoras pela Prefeitura Municipal de Arapoti: as professoras Plonia Lydia H. Goosen e Denise Aparecida Alves; duas professoras contratadas em caráter particular: Maria de Fátima Loyola Rosa e Edeutrand Neubauer Moser e a professora Anneke Elgersma, do quadro próprio do Magistério do Estado do Paraná. (PROJETO POLÍTICO PEDAGÓGICO, 2009, p. 5).

Na década de 1980, o Brasil passa por profundas mudanças. No final da primeira metade desta década, o Estado brasileiro se tornaria democrático. Todavia, não ocorreu a ruptura com o clientelismo político, a expansão dos direitos de cidadania e a consolidação dos movimentos sociais.

Os resquícios da ditadura militar continuam presentes nesse período, atingindo os diversos setores da vida nacional.

Ainda em relação às mudanças ocorridas na década de 1980,

[...] essa década foi marcada por um conjunto de fatores como o processo de abertura democrática; a ascenção às prefeituras e aos governos estaduais de candidatos pertencentes a partidos de oposição ao governo militar; a campanha reivindicando eleições diretas para presidente da República; a transição para um governo civil em nível federal; a organização e mobilização dos educadores, as conferências brasileiras de educação; a produção científica crítica desenvolvida nos programas de pós-graduação em educação; o incrementos das ideias pedagógicas propiciado pela criação de novos veículos. (SAVIANI, 2008, p. 413).

Sendo assim, em 1982, por meio de sua mantenedora, a Igreja Evangélica Reformada de Arapoti, foi implantada uma Diretoria composta pelos imigrantes: Yde Van der Goot, Tenntje J. Elgersma e Jan Borg, os quais tornaram-se responsáveis pela administração da escola, deixando a cargo da professora Edeltraud Naubauer Moser os aspectos pedagógicos. No mesmo ano, o Prefeito Municipal de Arapoti, Sr. Dirceu Novochadlo, através do Decreto $\mathrm{n}^{\mathrm{o}} 131 / 82$, criou as escolas rurais do município, dentre as quais incluiu-se a Escola Rural da Colônia Holandesa, sendo então autorizado, o funcionamento do ensino de $1^{\circ}$ Grau de $1^{\mathrm{a}}$ a $4^{\mathrm{a}}$ série. (PROJETO POLÍTICO PEDAGÓGICO, 2009, p. 5). 


\section{Revista HIIS'TEIDBR On-lime}

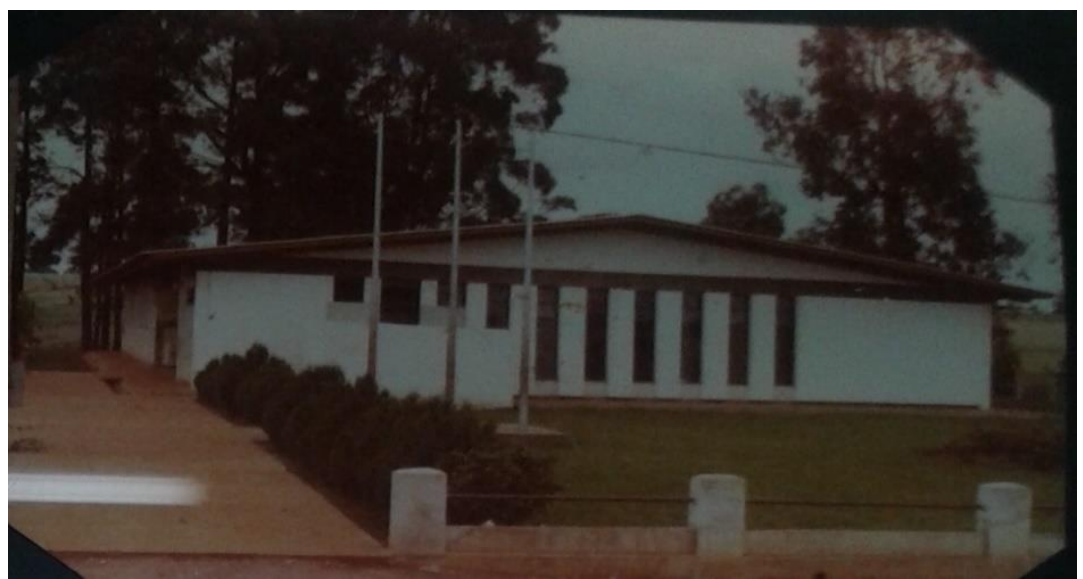

Fotografia 02 - Escola Colônia Holandesa.

Fonte: Museu o Imigrante Holandês- Arapoti-PR.

Outras mudanças ocorreram na escola a partir de 1984. Neste ano, foi contratada pelo Presidente da Diretoria Local da escola, a professora Maria José de Almeida Guerke, funcionária efetiva do Estado, que foi cedida por este para assumir a Direção do referido Colégio. Em relação a sua contratação, a depoente declara:

"Fui cedida pelo Estado por meio de um convênio de comodato. Eu deveria dirigir a escola e dar aulas ao mesmo tempo. Em troca, a prefeitura exigiu que o Colégio concedesse 20 bolsas de estudos a alunos brasileiros". (S2).

No mesmo ano em que finda o governo militar no Brasil (1985), a escola sob a direção da professora Maria José Guerke passa a funcionar em caráter particular, inicia a implantação de forma gradativa da $5^{\mathrm{a}}$ a $8^{\mathrm{a}}$ série do Ensino de $1^{\circ} \mathrm{Grau}$, bem como passa a denominar-se Escola Colônia Holandesa- Ensino de $1^{\circ} \mathrm{Grau}$.

“Assim que assumi a Direção da escola, contratei novas professoras brasileiras, pois eles(imigrantes) queriam muito aprender a nossa língua". (S2).

Em 1988 é promulgada a Nova Constituição Federal brasileira, depois de inúmeras dificuldades na fase de elaboração. Esta tentou dar conta das profundas mudanças ocorridas em nosso país na economia, nas relações de poder e nas relações sociais globais, nos últimos 20 anos, introduzindo temas, redefinindo papéis, incorporando às instituições sociais segmentos historicamente marginalizados, sem, no entanto, alterar substantivamente as relações sociais vigentes. (NEVES, 1999, p. 99).

A Constituição de 1988 trouxe aspectos positivos e negativos para o país. No campo educacional, a nova Constituição trouxe avanços em relação aos textos constitucionais anteriores, pois em seu artigo 206 estabelece que o ensino será ministrado nos seguintes princípios:

I-Igualdade de condições para o acesso e permanência na escola;

II-liberdade de aprender, ensinar, pesquisar e divulgar o pensamento, a arte e o saber;

III-pluralismo de ideias e de concepções pedagógicas, e coexistência de instituições públicas e privadas de ensino;

IV-gratuidade do ensino público em estabelecimento oficiais;

V-valorização dos profissionais de ensino; 


\section{Revista HIISTEYIDIR On-line}

VI-gestão democrática do ensino público, na forma da lei;

VII- garantia de padrão de qualidade. (BRASIL, 1988, p. 121).

Embora a Constituição de 1988 tenha trazido mudanças significativas para o país, cabe ressaltar que estas não foram implantadas efetivamente, uma vez que, existe ainda uma enorme distância entre o plano legal (os direitos garantidos constitucionalmente) e o plano real.

Dessa forma, a melhoria no rendimento escolar e na qualidade de ensino asseguradas constitucionalmente, continuam sendo uma das principais metas a serem alcançadas pelo país.

Nesse mesmo ano (1988) a professora Maria José Guerke, elaborou em consonância com o Núcleo Regional de Educação de Ponta Grossa, o primeiro Regimento Escolar do Colégio Colônia Holandesa. Este documento aponta como objetivos da escola:

1.2- Melhor rendimento do aluno em termos de aprendizagem mais dotados de significado. Otimização da aprendizagem;

1.2.1 - Possibilitar maiores oportunidades educacionais à população em idade escolar residente na zona rural do Município;

1.2.3- Prover ambientes escolares melhores e mais adequados;

1.2.4- Estabelecer métodos que possibilitem a melhoria qualitativa dos padrões técnicos do ensino. (REGIMENTO ESCOLAR, 1988).

Buscando atender ao objetivo 1.2.1 "Possibilitar maiores oportunidades educacionais à população em idade escolar residente na zona rural do Município", uma das entrevistadas declara que:

\footnotetext{
"Nessa época, o município ainda não tinha escolas suficientes para atender a todos, bem como as poucas escolas existentes ficavam longe da Colônia Holandesa. E quanto as bolsas de estudo, eu dava preferência para alunos brasileiros que moravam na zona rural, pois sabia que eles moravam longe da cidade e poderiam vir junto com os holandeses para a escola”. (S1).
}

Quanto aos critérios adotados para a concessão de bolsas de estudos a alunos brasileiros, a depoente acima explicita que não havia nenhum critério formalmente documentado. Assim, dava-se preferência a alunos residentes na zona rural do município, proveniente de família de baixa renda, e uma das condições exigidas para a manutenção dessa bolsa era a não reprovação em nenhuma série.

A escola continuou a ofertar apenas o Ensino de $1^{\circ}$ Grau até o ano de 2000 . Até este ano, os alunos que concluíam seus estudos no Colégio Colônia Holandesa, tinham apenas duas opções: prosseguiam seus estudos na cidade de Arapoti, no Colégio Estadual Rui Barbosa e/ou na Escola Estadual Telêmaco Carneiro ou mudavam-se para Castro, para estudar no Instituto Cristão.

Conforme mencionado anteriormente, as aulas eram ministradas em português no período matutino, e no período vespertino, em holandês. Em relação aos materiais didáticos utilizados nas aulas, uma das entrevistadas declara que:

"Como os materiais vindos da Holanda eram utilizados apenas nas aulas de Holandês, nós tínhamos poucos materiais didáticos, no entanto, eu escrevia para 


\section{Revista HIIST'TEIDBR On-line}

as editoras brasileiras e estas me enviavam inúmeros livros didáticos, os quais eram utilizados pelos alunos e professores". (S1).

Ainda para a referida professora, a falta de materias didáticos não impedia o desenvolvimento e crescimento da escola, pois a procura de vaga na mesma crescia constantemente. Assim, em 1995, foi construído pela própria escola, um novo prédio, com mais quatro salas de aulas, para atender a nova demanda.

Em 1996, é aprovada a nova Lei de Diretrizes e Bases da Educação brasileira, Lei ${ }^{\circ}$ 9394. O conteúdo desta Lei pouco veio a acrescentar ao que já havia sido posto na anterior, no entanto, "[...] uma de suas inovações foi apresentar uma concepção de educação mais ampla, inclusive com a introdução do conceito de educação escolar". (NETO, 2015, p. 211).

Dentre os avanços da educação com a aprovação da nova Lei de Diretrizes e Bases da educação destacam-se: a consagração do princípio de avaliação como parte central da organização da educação nacional; em relação à educação básica, a preocupação com a verificação do rendimento escolar; o professor como eixo central da qualidade da educação; o aperfeiçoamento continuado do professor; a avaliação do desempenho dos professores; a implantação do Fundo de Manutenção e Desenvolvimento do Ensino Fundamental e de Valorização do Magistério; definição dos parâmetros para aplicação dos recursos previstos em lei e a apresentação de formas de controle das receitas públicas aplicadas à educação, na tentativa de dar transparência ao processo. (NETO, 2015, p. 213).

As mudanças também continuaram no Colégio Colônia Holandesa. Em 1998, devido a aposentadoria da professora Maria José Guerke, assume a direção da Escola, a professora Rosi Rogenski Ferreira. Esta ampliou o quadro de funcionários, contratando mais professores para a escola, reorganizou os horários de funcionamento, bem como implantou no ano de 2000, o Ensino Médio. Ainda nesse ano, a Escola passa a denominar-se Colégio Colônia Holandesa- Educação Infantil, Ensino Fundamental e Ensino Médio.

Uma nova mudança na legislação educacional brasileira ocorre em 2005, com a sanção da Lei 11.274/06, a qual torna obrigatória o ensino fundamental de 9 anos no país, com a matrícula dos alunos aos 6 anos de idade. Assim, atendendo ao disposto na referida lei, o Colégio Colônia Holandesa passa a ofertar, em 2009, o ensino fundamental de 9 anos conforme o ato administrativo $n^{\circ}$ 75/09 expedido pelo Núcleo Regional de Educação de Wenceslau Braz.

\section{A EDUCAÇÃO DO COLÉGIO COLÔNIA HOLANDESA E SUA RELAÇÃO COM A POLÍTICA LIBERA}

O Colégio Colônia Holandesa surgiu em 1960. Essa década segundo Saviani (2008, p. 336) "[...] foi uma época de intensa experimentação educativa, deixando clara a predominância da concepção pedagógica renovadora".

Através das narrativas das entrevistas realizadas, pudemos perceber que no início, a educação do $\mathrm{CCH}$ era fortemente tradicional, centralizadora.

Para um de nossos depoentes, a lembrança que ficou guardada em sua memória era que a escola era muito "diferente de hoje em dia: "Nós tínhamos que decorar a letra dos 


\section{Revista HIISTEYIDIR On-line}

Artigo

doi: $10.20396 /$ rho.v17i4.8651242

hinos. Quando não fazíamos tudo direito, ela nos castigava: batia com a régua na nossa mão ou nos fazia ajoelhar em grãos de milho". (S1).

Ele considerava a professora muito rígida, com “[...] jeito alemão”. Ainda em relação a postura dos professores, outra depoente declara que: "[...] as cobrança e os castigos eram bem rigorosos. Se nossos pais fossem chamados na escola, levávamos xingos na sala e uma surra em casa, o castigo era duplo; nós cantávamos e decorávamos a letra de vários hinos por causa da dicção em holandês". (S1).

Por meio dos relatos acima, podemos perceber que, inicialmente, a educação no $\mathrm{CCH}$ era tradicional, caracterizada pela memorização de hinos religiosos, bem como sua organização era centrada no professor. "A este cabia transmitir, segundo uma gradação lógica, o acervo cultural aos alunos". (SAVIANI, 2009, p. 6).

A educação tradicional "[...] apoiava-se na certeza de que o ato educativo destinavase a reproduzir os valores e a cultura da sociedade". (GADOTTI, 1999, p. 268).

Na narrativa de nossos depoentes sobre a organização da escola, percebemos a existência de práticas pedagógicas condizentes ao ensino tradicional:

"Era bem puxado, éramos muito cobrados quanto a caligrafia e a oralidade. A caligrafia tinha que ser impecável”. (S2).

"Na sala de aula eu lembro que as carteiras eram enfileiradas, lembro do quadronegro, da professora nos fazendo bastante perguntas, nos cobrava bastante a leitura e a escrita”. (S3).

"A escola sempre foi mais tradicional, e eu também sempre fui muito tradicional, acho que talvez seja o método que a gente estudou, e é o que a gente leva. E nós também temos, ainda hoje, uma geração de professores tradicionais" complementa outra depoente. (S1).

Saviani (2008, p. 343) explicita que em 1964, o Instituto de Pesquisas e Estudos Sociais (IPES) realizou um simpósio sobre a reforma da educação e o Fórum "A educação que nos convém". O conjunto de sugestões apresentadas nesses eventos para o encaminhamento da política educacional do país, ressaltava em sentido geral:

[...] elementos dispostos pela teoria do capital humano; na educação como formação de recursos humanos para o desenvolvimento econômico dentro dos parâmetros da ordem capitalista; na função de sondagem de aptidões e iniciação para o trabalho atribuída ao primeiro grau de ensino; no papel do ensino médio de formar, mediante habilitações profissionais, a mão de obra técnica requerida pelo mercado de trabalho; na diversificação do ensino superior, introduzindo-se cursos de curta duração voltados para o atendimento da demanda de profissionais qualificados [...]. (SAVIANI, 2008, p. 345).

Saviani (2008, p. 345) afirma ainda que a concepção pedagógica articulada pelo Instituto de Pesquisas e Estudos Sociais (IPES), veio a ser incorporada nas reformas educativas instituídas pela lei da reforma universitária, pela lei relativa ao ensino de $1^{\circ}$ e $2^{\circ}$ graus e pela criação do Movimento Brasileiro de Alfabetização (Mobral). 
A concepção pedagógica articulada pelo IPES também influenciou a educação do $\mathrm{CCH}$, pois a Escola passou a ofertar, a partir de 1985, um curso técnico em técnicas agrícolas para os alunos do Ensino de $1^{\circ}$ Grau a partir da $5^{\mathrm{a}}$ série. Segundo o relato de uma das entrevistadas: "Esse curso de técnicas agrícolas vinha de encontro às necessidades dos alunos, pois a maioria, após a escola, ajudava os pais na agricultura”. (S1).

Já a maioria dos alunos, ao concluírem o $1^{\circ}$ grau, mudavam-se para Castro para estudar no Instituto Cristão, pois este ofertava cursos técnicos com habilitações profissionais, as quais atendiam a mão-de-obra técnica requerida pelo mercado de trabalho.

Contudo, apesar de os métodos de ensino e a organização da escola expressarem uma escola tradicional, os depoentes narram que a escola era um ambiente prazeroso, esse fato é atribuído ao espaço físico amplo, aberto, sem muros e/ou cercas ao redor da mesma:

“[...] lembro que brincávamos por todo o pátio, à vontade, com muita liberdade. Até hoje o espaço é amplo, tudo aberto”. (S1).

"[...] brincavámos bastante nos recreios. Como a escola sempre foi aberta, tinha bastante espaço para corrermos, brincar de esconde-esconde, cabaninha”. (S2).

"Lembro também das brincadeiras. Tinha um bosque, onde nós fazíamos tendas. Até hoje a escola é bem livre, não tem necessidade de portões”. (S3).

"Eu acho que o CCH é diferente, desde a sua arquitetura e sua maneira de agir com as crianças. Ela tem um clima diferente, é uma escola toda aberta” (S2).

Existem também indícios que alguns professores buscaram superar o ensino pautado apenas na memorização de hinos devocionais, por meio de atividades diversificadas, facilitadoras da aprendizagem dos alunos. Nos relatos sobre a prática pedagógica de alguns professores, uma depoente declara:

"[...] a dona Lucy nos mostrava figuras e depois nos pedia para escrever [...] as aulas eram muito dinâmicas, a gente era muito motivado, era tudo muito empolgante, sempre apresentávamos trabalhos orais, teatros para a comunidade relacionados à Holanda”. (S2).

"A Dona Lucy tinha um baú cheio de figuras e nos pedia para escolher um tema, uma figura livremente. Depois nós pesquisávamos sobre esse tema para apresentar oralmente para os demais colegas", complementa outra depoente (S3).

A escola também sempre esteve focada nos resultados das avaliações. Nos depoimentos, isso fica explícito: "No holandês não havia reprovação, mais tinha metas para cumprir durante o ano todo. Dificilmente não cumpríamos as metas, mas quando isso acontecia, os rebeldes ficavam em pé na porta da sala”. (S2).

"A escola também sempre se preocupou com resultados, as crianças tinham que ter um resultado bom. [...] Era um ensino muito pautado no resultado, nós tínhamos metas para cumprir". (S2).

Por meio dos depoimentos acima é possível perceber uma relação entre a educação do $\mathrm{CCH}$ com a política liberal. O liberalismo ${ }^{8}$ teve sua origem em um período de profundas transformações no modo de produção na Europa e nos Estados Unidos, em virtude de que 
eram necessárias a legitimação e a aceitação das mudanças que estavam ocorrendo e que estavam por vir, sendo caracterizada esta fase como liberalismo clássico. (ZANLORENZI, 2014, p. 28).

" $\mathrm{O}$ individualismo, a liberdade, a igualdade, a propriedade, a segurança e uma nova concepção de justiça constituem as categorias básicas da ideologia liberal”. (HORTA, 1987, p. 198).

Calcado na obra L'Ideologie Liberale de Vachet (1970), Horta (1987) explicita que o liberalismo se apodera do individualismo para formular ideologicamente seus princípios e suas tarefas; a liberdade é proclamada pelo liberalismo como primeiro dos direitos individuais naturais, consequência de sua autonomia e de sua suficiência racional, e sobretudo como condição de sua busca de felicidade.

A igualdade liberal é inseparável da liberdade, pois se reduz ao direito igual de cada homem à liberdade, não lhes negando o direito ou o poder de se diferenciar e de atualizar as diferenças individuais, se complementando pela "igualdade de oportunidades", pela abolição das restrições legais à livre competição dos indivíduos.

A propriedade para o liberalismo é vista como um direito natural e fundamental, a base da visão capitalista da economia, em que o capital é considerado não apenas um instrumento de facilitação das trocas, mas também como fonte de crescimento de bens que dão poder e riqueza.

$\mathrm{O}$ direito à segurança refere-se ao papel do Estado Liberal como agente da ordem e da paz, fazendo- o garantir a propriedade pela prevenção e a repressão das usurpações e por meio do respeito imposto à territorialidade das nações, e pela liberação e desenvolvimento do comércio internacional, consolidando a paz e assegurando ao proprietário mercado para a sua produção.

Já a justiça assegurada pelo liberalismo significa a relação moralmente necessária da propriedade ao proprietário, do lucro ao capitalista. "Assim, a intervenção do Estado, através de sua legislação, visa apenas como pensar a irracionalidade da maioria dos homens e manter a divisão de classes". (HORTA, 1987, p. 202).

Para o liberalismo, a igualdade entre os indivíduos se materializa na igualdade de oportunidades, quando os indivíduos têm sucesso é graças a seu mérito individual. Dessa forma,

[...] o trabalho desenvolvido pelo professor na escola será fundamental na medida que oportunize e possibilite condições de acesso de conhecimento igual a todos os indivíduos, no entanto, obter sucesso é competência de cada um, uma vez que a utilização das oportunidades seria consequência de suas escolhas e de seu mérito. (ZANLORENZI, 2014, p. 60).

Observamos na narrativa dos depoentes uma relação entre a educação do $\mathrm{CCH}$ com a política liberal. Esta relação pode ser observada na declaração abaixo que discorre sobre a preocupação da escola com os resultados:

"A escola também sempre se preocupou com resultados, as crianças tinham que ter um resultado bom, tínhamos metas para cumprir”. (S2). 
A afirmação acima demonstra que a escola se preocupava em ofertar um ensino de qualidade, para isso buscava garantir a oportunidade de igualdade a todos os alunos. No entanto, se algum aluno não alcançasse um bom resultado, isso seria explicado pela falta de competência e mérito individual.

No entanto, essa igualdade- proclamada como um dos princípios básicos do liberalismo - era falha no $\mathrm{CCH}$, uma vez que, nem todos os cidadãos arapotienses poderiam frequentar a mesma, visto que desde o seu surgimento, a escola cobrava mensalidades e a porcentagem de bolsas concedidas à alunos carentes não atendia a demanda da população.

Entretanto, na tentativa de reduzir os problemas da marginalização social, "[...] o Estado liberal atua em sua forma assistencialista ao prover as condições mínimas de sobrevivência mediante programas e projetos [...] como possibilidade de mudar a realidade pautada pelas desigualdades sociais". (CARVALHO; MELO, 2012, p. 55).

Dessa forma, por mais que o $\mathrm{CCH}$ conceda anualmente bolsas de estudos a alunos carentes, isso não garante a redução das desigualdades sociais por dois fatores: primeiro, porque a quantidade de bolsas ofertadas é insuficiente para atender a demanda da população; já o segundo, pode ser explicado pela igualdade -uma das categorias básicas da ideologia liberal - de oportunidades, ou seja, caso algum aluno bolsista não alcance um bom resultado nas avaliações da escola, não seja aprovado em algum vestibular ou não consiga um bom emprego, isso seria explicado pela falta de competência e mérito individual e não pela desigualdade social.

Desde o seu surgimento, o $\mathrm{CCH}$ tem como um de seus principais objetivos preparar os alunos para o vestibular. Isso fica explícito na declaração:

"Na época em que eu estava, era muito cobrado a questão do resultado para o vestibular, e ainda hoje continua, mas a gente não focava só nisso!" (S2).

Se por um lado, identificamos na narrativa dos depoentes traços da teoria liberal na educação do $\mathrm{CCH}$, por outro, também é possível perceber características da reforma neoliberal do Estado.

As reformas para a educação que se baseiam nos pressupostos da reforma neoliberal do Estado assentam-se nas ideias de que: a descentralização da gestão administrativa possibilita o aumento da eficácia e da eficiência do funcionamento das escolas e facilita o processo de prestação de contas baseado no conceito de responsabilidade; é fundamental definir-se um currículo nacional, que estabeleça uma base comum de conteúdos para a educação básica; a importância da qualificação de professores, exigindo dos professores das séries iniciais uma formação em nível superior, investindo-se ao mesmo tempo na formação continuada. (TORRES, 1996, p. 148).

A teoria neoliberal se caracteriza por uma adaptação ou reforma em função das mudanças ocorridas durante a trajetória do capital. Tem sua base de apoio no liberalismo clássico do século XVII, de ideais firmados na exacerbação do individualismo como realização plena do homem, Estado Mínimo e independência do mercado como condição para o pleno desenvolvimento social. (CARVALHO; MELO, 2012, p. 53). 
A lógica de administração do CCH baseia-se nos pressupostos da reforma neoliberal do Estado, pois procura analisar o perfil e o desempenho dos profissionais antes mesmo de sua contratação, conforme explicitado por esta depoente:

\begin{abstract}
"A diretoria também dava a palavra final na contratação de professores, mas nós tivemos alguns problemas e eu precisei mudar o esquema: eu contratei um profissional para fazer um teste do perfil profissional do candidato, porque se o professor não tem o dom, não tem o desejo, a vontade de ser professor, ele não pode ser! Ele vai acabar prejudicando um grupo de crianças. Então, nós passamos a fazer o teste e uma entrevista, mas o teste era determinante. Uma empresa terceirizada fazia esse teste". (S2).
\end{abstract}

No neoliberalismo, o papel subsidiário assumido pelo Estado em relação à educação significa também o apoio à iniciativa privada, pois esse investimento sempre é menor que o requerido para a sustentação de uma estrutura maior. Se o Estado ajuda os setores privados a desenvolverem a tarefa educativa, liberaram-se dos gastos de manutenção dos estabelecimentos e da estrutura burocrática. Esta estratégia tem sido desenvolvida nos últimos anos por diferentes governos latino-americanos, o que levou a uma perda da qualidade da educação pública e uma tendência crescente de substituição pela educação privada, vista como portadora de maior qualidade e eficiência. (BIANCHETTI, 1999, p. 98).

Esse papel subsidiário do Estado no neoliberalismo foi desempenhado desde o surgimento do $\mathrm{CCH}$. Isso pode ser observado por meio do relato de uma depoente:

"Fui cedida pelo Estado por meio de um convênio de comodato. Eu deveria dirigir a escola e dar aulas ao mesmo tempo. Em troca, a prefeitura exigiu que o Colégio concedesse 20 bolsas de estudos a alunos brasileiros. (S1).

O relato acima mostra que, se por um lado, o governo brasileiro incentivava a vinda de imigrantes europeus com o intuito de "reocupar os espaços vazios" do território brasileiro, por outro, não estava preocupado em assumir a responsabilidade com a educação desses imigrantes, como ocorreu com os holandeses em Arapoti-PR. Assim, o Estado procurou dar apenas um apoio subsidiário a esses, cedendo-lhes uma professora, a qual deveria ensiná-los a Língua Portuguesa, auxiliando-os na inserção mais rápida na nova pátria.

Apesar de contar com um apoio apenas subsidiário do Estado, o Colégio Colônia Holandesa possui uma identidade própria.

\title{
CONSIDERAÇÕES FINAIS
}

Analisar o processo histórico de reconstituição do Colégio Colônia Holandesa em Arapoti, nos propiciou o conhecimento de alguns fatores que contribuíram para a saída dos imigrantes holandeses de sua pátria e a vinda para o Brasil, e mais especificamente, para Arapoti-PR.

No século XIX, diversos países europeus enfrentaram inúmeros conflitos devido à Revolução Industrial e ao aumento populacional que ocorriam nesse período. Assim, a Holanda também foi atingida, uma vez que, esta devido à sua localização geográfica e ao tamanho reduzido, teve a imigração estimulada por parte dos governos holandês e brasileiro. 
Para este último, a imigração era vista como algo profícuo, pois além de reocupar os chamados espaços vazios do território brasileiro, a imigração auxiliaria também no branqueamento do país, atendendo assim, aos interesses do governo de construir uma nova nação, calcada na crença da superioridade inata dos europeus para o trabalho.

Dessa forma, podemos dizer que os imigrantes holandeses, deixaram sua pátria em busca de novas possibilidades, que lhes proporcionassem melhores condições de vida.

Os holandeses chegaram em Arapoti em 1960, e nesse mesmo ano, deram início a construção de suas casas, de uma igreja, uma escola e uma cooperativa agroindustrial. Amparados pela Colônia Holandesa de Carambeí-PR, instalados neste município desde 1911, os holandeses de Arapoti, se preocuparam desde o início com o ensino de seus filhos. Assim, inicialmente, a escola e a igreja funcionavam no mesmo espaço.

Embora a organização da escola aponte alguns elementos e práticas de ensino condizentes com uma escola tradicional, por meio do relato de alguns depoentes, ficou evidenciado que alguns professores buscaram superar um ensino pautado apenas na memorização, por meio de atividades diversificadas, facilitadoras da aprendizagem.

O liberalismo, doutrina político-econômica, proveniente da Europa e dos Estados Unidos nos fins do século XVII, tem como princípios básicos a igualdade entre os indivíduos, a liberdade, a propriedade e a segurança.

No entanto, na relação entre a educação do $\mathrm{CCH}$ com a política liberal, alguns princípios liberais não são assegurados pela escola, como por exemplo, a igualdade, uma vez que, nem todos os cidadãos arapotienses poderiam frequentá-la, visto que desde o seu surgimento em 1960, a escola cobrava mensalidades e a porcentagem de bolsas de estudo concedidas a alunos carentes não atendiam a demanda da população.

Encontramos ainda características da reforma neoliberal do Estado, evidenciada no papel subsidiário do Estado em relação ao colégio, marcado pela cessão de professores brasileiros à escola, com o intuito de ensiná-los a Língua Portuguesa e a adaptação aos costumes da nova Pátria, bem como apoiando à iniciativa privada, visto que esse investimento era bem menor que o requerido para a sustentação de uma estrutura maior.

Sendo assim, temos consciência que a busca por dados realizada por esta pesquisa não se esgota aqui. Sendo assim, por meio de um recorte local, a educação dos imigrantes holandeses em Arapoti-PR, esperamos que a presente pesquisa possa além de incentivar novas pesquisas sobre a imigração holandesa, contribuir para a ampliação do conhecimento na área da História da Educação Brasileira.

\section{REFERÊNCIAS}

ALBERTI, V. Ouvir Contar: textos em história oral. Rio de Janeiro: FGV, 2004.

BIANCHETTI, L. Modelo neoliberal e políticas educacionais. 2. ed. São Paulo: Cortez, 1999. 
BRASIL. Constituição (1988). Constituição da República Federativa do Brasil. Brasília, DF: Senado Federal: Centro Gráfico, 1988. Disponível em: <http://www2.camara.leg.br/ atividadelegislativa/legislacao/Constituicoes_Brasileiras/constituicao1988.html >. Acesso em: 03 mar. 2015.

BRASIL. Lei no 4.024, de 20 de dezembro de 1961. Fixa as Diretrizes e Bases da Educação Nacional. 1961. Disponível em: <http://www.planalto.gov.br/ccivil_03/Leis/ L4024.htm\#art116>. Acesso em: 03 mar. 2015.

BRASIL. Lei ${ }^{\circ}$ 5.692, de 11 de agosto de 1971. Fixa as Diretrizes e Bases do ensino de $1^{\circ}$ e $2^{\circ}$ graus e dá outras providências. 1971. Disponível em: <http://www.planalto.gov.br/ ccivil_03/Leis/L5692.htm>. Acesso em: 03 mar. 2015.

BRASIL. Lei ${ }^{\circ}$ 9.394, de 20 de dezembro de 1996. Estabelece as diretrizes e bases da educação nacional. 1996. Disponível em: <http://www.planalto.gov.br/ccivil_03/leis/ 19394.htm>. Acesso em: 03 mar. 2015.

BRASIL. Lei $\mathrm{n}^{\circ}$ 11.274, de 20 de fevereiro de 2006. Dispõe sobre a organização do ensino fundamental de nove anos. 2996. Disponível em: <http://www.planalto.gov.br/ccivil_03/ leis/111.274.htm>. Acesso em: 03 mar. 2015.

CAMARGO, C. R. S.; BENATTE, A. P. Semióforos da etnicidade o museu imigrante Holandês de Arapoti, Paraná. Ateliê de História, n. 2, v. 1, p. 221-231, 2014.

CARVALHO, L. B.; MELO, E. M. Articulações da política (neo)liberal e seus impactos na educação. Interfaces da Educação, Paranaíba, v. 2, n. 6, p. 50-61, 2012.

CHAVES, N. (Org.). Imigrantes-immigranten: história da imigração holandesa na região dos campos gerais, 1911-201. Ponta Grossa: Estúdio Texto; APHC; NMC, 2011. (Falando de histórias II: imigrantes, educação, culinária, meio ambiente, tecnologia, memórias, n. 2).

CORDEIRO, S. V. A. L. A constituição da escola evangélica de Carambeí: uma instituição educacional da imigração holandesa na região dos Campos Gerais, 2007. Dissertação (Mestrado em Educação) - Universidade Estadual de Ponta Grossa, Ponta Grossa, 2007.

ESCOLA COLÔNIA Holandesa. Arapoti-PR: Museu o Imigrante Holandês, 1980. 1 fotografia.

ESTATUTO SOCIAL DA ASSOCIAÇÃO DO COLÉGIO COLÔNIA HOLANDESA DE ARAPOTI. Colégio Colônia Holandesa- Educacão Infantil, Ensino Fundametal e Médio, Arapoti, 2004.

GADOTTI, M. História das idéias pedagógicas. 8. ed. São Paulo: Ática, 1999.

GADOTTI, M.; ROMÃO, J. E. Autonomia da escola: princípios e proposta. 6. ed. São Paulo: Cortez, 2004. 
GOLDENBERG, M. A arte de pesquisar: como fazer pesquisa qualitativa em Ciências Sociais. 6. ed. Rio de Janeiro: Record, 2002.

GOOGLE MAPS. Localização de Arapoti. 1 imagem. Montagem das autoras. Disponível em: 〈https://www.google.com.br/maps/place/Arapoti+-+PR>. Acesso em: 10 dez. 2017.

HORTA, J. S. B. Liberalismo, tecnocracia e planejamento educacional no Brasil. São Paulo: Autores Associados; Cortes, 1987.

KAPP, A. C.; STREMEL, M. R.; CHAVES, N. B. História do Brasil IV. Ponta Grossa: UEPG/NUTEAD, 2011.

KLEIN, H. Migração internacional na história das Américas. In: FAUSTO, B. (Org.). Fazer a América. São Paulo: Ed. da EDUSP, 1999. p. 13-31.

KREUTZ, L. Escolas étnicas na história da educação brasileira: a contribuição dos imigrantes. In: STEPHANOU, M.; BASTOS, M. H. C. (Org.). Histórias e memórias da educação no Brasil: séculos XIX. Petrópolis, RJ: Vozes, 2005. p. 150-165. v. 2.

LADEIRA, H. O. Um estudo sobre a imigração holandesa nos Campos Gerais. UEPGCadernos Universitários, Ponta Grossa, n. 12, 1976.

NASCIMENTO, M. I. M. A primeira escola de Professores dos Campos Gerais - PR. Ponta Grossa, PR: Ed. da UEPG, 2008.

NETO, A. S. História da educação brasileira: do período colonial ao predomínio das políticas educacionais neoliberais. São Paulo: Salta, 2015.

NETTO, J. P. Pequena história da ditadura brasileira (1964-1985). São Paulo: Cortez, 2014.

NEVES, L. M. W. Educação e política no Brasil de hoje. 2 ed. São Paulo: Cortez, 1999.

PROJETO POLÍTICO PEDAGÓGICO. Colégio Colônia Holandesa - Educação infantil, ensino fundamental e médio, Arapoti, 2009.

REGIMENTO ESCOLAR. Colégio Colônia Holandesa - Educação infantil, ensino fundamental e médio, Arapoti, 1988.

REGIMENTO ESCOLAR. Colégio Colônia Holandesa - Educação infantil, ensino fundamental e médio, Arapoti, 2009.

ROMANELLI, O. O. História da educação no Brasil (1930/1973). 11. ed. Petrópolis: Vozes, 1978.

SALA DE aula. Arapoti, PR: Museu o Imigrante Holandês, 1960. 1 fotografia. 
SAVIANI, D. As concepções pedagógicas na historia da educação brasileira.

Campinas, 2009. Financiado pelo CNPq.

SAVIANI, D. História das ideias pedagógicas no Brasil. 2. ed. Campinas, SP: Autores Associados, 2008.

TORRES, R. M. Melhorar a qualidade da educação básica: as estratégias do Banco Mundial. In: TOMASI, L.; WARDE, M. J.; HADDAD, S. (Org.). O Banco Mundial e as políticas educacionais. São Paulo: Cortez, 1996. p. 125-191.

ZANLORENZI, C. M. P. A expressão do liberalismo na revista A Escola (1906-1910) no Paraná. 2014. Tese (Doutorado em Educação) - Universidade Estadual de Ponta Grossa, Ponta Grossa, PR, 2014. Disponível em: 〈www.lareferencia.info/vufind/.../BR_〉. Acesso em: 01 jun. 2015.

\section{Notas}

\footnotetext{
${ }^{1}$ Licenciada em Pedagogia pelas Faculdades Integradas de Itararé (2002) e em História pela Universidade Estadual de Ponta Grossa (2012). Mestre em Educação pela UEPG.

${ }^{2}$ Doutora em Filosofia e Ciências da Educação pela Universidade de Santiago de Compostela. Professora da Pós Graduação em Educação - Mestrado e Doutorado e do Departamento de Educação da Universidade Estadual de Ponta Grossa. Coordenadora da Universidade Aberta para a Terceira Idade. E-mail: soliveira13@uol.com.br.

${ }^{3}$ Entrevista concedida por KOK, H. Entrevista I. [mar. 2013]. Entrevistador: Carla Roseane de Sales Camargo. Arapoti, 2013. 1 arquivo. mp4 (50:20 min.). In: CAMARGO, C. R. S.; BENATTE, A. P.

Semióforos da Etnicidade o museu imigrante Holandês de Arapoti, Paraná.. Ateliê de História, n. 2, v. 1, p. 221-231, 2014.

${ }^{4}$ MAPA de Arapoti-Paraná. 1 mapa, color.

Disponível em: <https://www.google.com.br/maps/place/Arapoti+-+PR/@-24.0723209,-50.2603641, 10z/data=!3m1!4b1!4m5!3m4!1s0x94c207297a7d7cab:0x46bde8f7aa628465!8m2!3d-24.1507449!4d49.826658 >. Acesso em: 10 jan. 2018.

${ }^{5}$ Entrevista concedida por HAGEN, J. Entrevista I. [mar.2015]. Entrevistador: Carla Roseane de Sales Camargo. Arapoti, 2015. 1 arquivo. mp4 (43:09 min.).

${ }^{6}$ Para saber mais sobre esses dados quantitativos, ler: ROMANELLI, O. O. História da Educação no Brasil (1930/1973). 11 ed. Petrópolis: Vozes, 1989.

${ }^{7}$ Para saber mais sobre os Acordos MEC/USAID, ler: FAZENDA, I. C. Educação no Brasil anos 60: o pacto do silêncio. 2 ed. São Paulo: Loyola, 1988. p. 60-64.

${ }^{8}$ Para conhecer mais sobre a história do Liberalismo ver: Laski (1973).
}

Submetido em: 13/11/2017

Aprovado em: 13/12/2017 